Research Article

\title{
Experimental Investigation of the Size Effect of the Mode I Static Fracture Toughness of Limestone
}

\author{
Sheng Zhang, ${ }^{1,2}$ Longfei Wang, ${ }^{1}$ and Mingzhong Gao $\mathbb{i D}^{3}$ \\ ${ }^{1}$ School of Energy Science and Engineering, Henan Polytechnic University, Jiaozuo, Henan 454001, China \\ ${ }^{2}$ Collaborative Innovation Center of Coal Work Safety, Jiaozuo, Henan 454001, China \\ ${ }^{3}$ Institute of Deep Earth Sciences and Green Energy, College of Civil Engineering, Shenzhen University, Shenzhen 518060, China
}

Correspondence should be addressed to Mingzhong Gao; gmz1980@sohu.com

Received 18 February 2019; Accepted 23 May 2019; Published 27 June 2019

Academic Editor: Mostafa Sharifzadeh

Copyright ( $\odot 2019$ Sheng Zhang et al. This is an open access article distributed under the Creative Commons Attribution License, which permits unrestricted use, distribution, and reproduction in any medium, provided the original work is properly cited.

To study the size effect of the fracture toughness of notched semicircular bend (NSCB) specimens, the dimensionless energy release rate equation of the NSCB specimen was deduced on the basis of the Bažant energy release rate. The influence of the crack length and the specimen size on the fracture toughness was analyzed. The Bažant scale equation was obtained using the International Union of Laboratories and Experts in Construction Materials, Systems, and Structures (RILEM) method. Finally, the Bažant equation was used to analyze the fracture toughness of an NSCB specimen with a radius of $75 \mathrm{~mm}$, and the degree of variation was predicted. The results show that a longer fracture is correlated with a lower fracture toughness value for the same sample size and that a larger specimen radius is correlated with a higher fracture toughness value for the same crack length. The obtained Bažant equation correctly reflects the scale law of the fracture toughness of the NSCB specimen and provides highly accurate predictions of the fracture toughness of large specimens, with an error of not more than $3 \%$. The results obtained in this study provide a new reference method and theoretical basis for the future testing work.

\section{Introduction}

The fracture toughness of rock is an important basic mechanical parameter that characterizes the ability of the material to resist crack initiation and propagation [1]. However, the fracture toughness of rock is not easily measured and is affected by factors such as the laboratory equipment, specimen shape, temperature, confining pressure, and loading rate [2-9], with the specimen size being one of the most important factors. As a result, it is important to study the size effect of rock fracture toughness; such a study requires the use of the mechanical parameters measured in the laboratory to guide the design of large structures in civil engineering.

Certain remaining controversies regarding the causes of the size effect are the topic of active research. Bažant $[10,11]$, based on the energy release theory, proposed a simple equation for the static size effect that describes the size effect of the nominal strength of a quasibrittle material structure after large stabilized crack propagation. This equation is the famous Bažant size effect law. Wu et al. [12] proposed a geometric shape function of a cracked chevron notched Brazilian disc (CCNBD) based on Bažant's equation of the fracture toughness scale law under similar conditions; this approach solved the limitation that the equation of the Bažant scale law is not valid in the case of nonsimilarity of the CCNBD specimen structure. Zhang et al. [13] studied the size effect of the dynamic fracture toughness of rock under impact loading using the holed-cracked flattened Brazilian disc (HCFBD). Feng et al. [2] used the Hopkinson pressure bar system to perform a radial impact test on Brazilian disc samples with three geometrical similarities and different sizes of flattened Brazilian disc (CSTFBD) that were cracked straight through and determined the dynamic fracture toughness of rock using experiments and a numerical method. The test results showed that the dynamic fracture toughness of rock is affected not only by the loading rate but also by the size effect. Yu et al. [14] using self-developed rock 
rupture process numerical calculation software, performed a numerical simulation of granite samples with particle sizes of $1.02 \mathrm{~mm}, 2.12 \mathrm{~mm}$, and $3 \mathrm{~mm}$ and studied the dimensional effect of fracture toughness from the microscopic perspective. In other research, Arslan and Ince [15] used the neural network method to analyze the size of the fracture process zone. Ayatollahi and Akbardoost [16] analyzed the size effect of the complex fracture toughness of marble and recommended a quantitative analysis method of the fracture zone. Wong and co-researchers $[17,18]$ performed marble and gypsum material compression tests and observed crack propagation processes; these tests involved a variety of particle sizes associated with marble and gypsum materials and thus involved various particle size distributions. The results showed that the crack initiation stress decreases with decreasing particle size and that the uniaxial compressive strength is not strongly coupled to the particle size of the fractured rock. Dai and his co-researchers $[19,20]$ carried out numerical simulation to assess fracture process zones and the progressive rock fracture mechanism of CCNBD specimens. In addition, when the rock specimens have the small size, the nonsingular stress terms (e.g., the T stress) are also important factors to affect fracture toughness. As to this issue, Aliha and Ayatollahi [21,22] researched the influence of the nonsingular stress term $\mathrm{T}$ on the rock fracture toughness. Wei et al. [23, 24] used generalized maximum tangential strain criterion (GMTS) and further improved maximum tangential stress criterion (FIMTS) to predict I/II fracture toughness of rocks with the consideration of $\mathrm{T}$ stress.

In summary, in most of the studies on the size effect of rock fracture toughness, the researchers have used CCNBD specimens previously recommended by the International Society for Rock Mechanics (ISRM) or developed their own CSTFBD or HCFBD specimens. In this context, we investigated the size effect of rock fracture toughness using the notched semicircular bend (NSCB) [25-27] specimens which were proposed by the ISRM in 2014. The NSCB specimens have a wider size, disk radius values of $25 \mathrm{~mm}$, $37.5 \mathrm{~mm}, 50 \mathrm{~mm}$, and $75 \mathrm{~mm}$, and a ratio of crack length to disk specimen radius of 0.4 to 0.6 ; in particular, the prefabricated crack width of this specimen type requires special processing methods, with a prefabricated crack width of less than $0.6 \mathrm{~mm}$. Based on the Bažant energy release rate theory, the size effects of NSCB specimens under different prefabricated crack lengths were studied.

\section{Preparation and Test Methods}

2.1. Formula for Determining the Fracture Toughness of Rock Using the NSCB Specimen. Figure 1 shows the loading of the NSCB sample. a represents the length of the artificial prefabricated crack, $P$ in Figure 1(a) represents the load applied to the specimen, and $S$ represents the distance between the two support points of the specimen. $B$ in Figure $1(b)$ is the thickness of the specimen, and $R$ is the radius of the specimen. According to the recommended method of [25], the equation for the mode I fracture toughness of an NSCB sample is given by the following equation:

$$
K_{\text {Ic }}=\frac{P_{\mu} \sqrt{\pi a}}{2 R B} Y,
$$

where $P_{\mu}$ represents the peak load of the NSCB sample measured in the test, $\pi$ is a constant, and $Y$ is the dimensionless stress intensity factor of the NSCB specimen (which is related to the geometric configuration of the sample). According to the international suggested method, $Y$ is calculated as follows:

$$
\begin{aligned}
Y= & -1.297+9.516\left(\frac{S}{2 R}\right)-\left(0.47+16.457\left(\frac{S}{2 R}\right)\right) \alpha \\
& +\left(1.071+34.401\left(\frac{S}{2 R}\right)\right) \alpha^{2},
\end{aligned}
$$

where $\alpha$ represents the dimensionless crack length, that is, $\alpha=a / R$. The mode I fracture toughness can be calculated using equations (1) and (2).

2.2. Preparation of the NSCB Specimen. The specimen material is limestone obtained from Jiaozuo city, Henan Province. The main material of the rock is calcite, the hardness is low, the natural microfracture density is small, the structure is dense, the texture is uniform, and the mineral particles are small. The density of the rock material is $\rho=2.6 \mathrm{~g} / \mathrm{cm}^{3}$, Young's modulus is $E=63.938 \mathrm{GPa}$, Poisson's ratio is $v=0.27$, longitudinal wave velocity is $V_{\mathrm{p}}=5.674 \times 10^{3} \mathrm{~m} / \mathrm{s}$, and compressive strength is $\sigma_{\mathrm{c}}=$ $169.35 \mathrm{MPa}$.

The specimens were prepared using the following four steps: drilling the rock, creating the discs, grinding the rock face, and making an artificial seam, as shown in Figure 2.

(1) We drilled the rock core on limestone slabs with sleeve diameters of $50 \mathrm{~mm}, 75 \mathrm{~mm}, 100 \mathrm{~mm}$, and $150 \mathrm{~mm}$.

(2) Four kind of diameters of drill cores were cut into a disk with the ratio of thickness to diameter 0.32 , and then the upper and lower end faces of the disc specimen were polished using a grinding machine to an unevenness of less than $0.5^{\circ}$ and ensure that the ratio of specimen thickness to specimen diameter is 0.3 .

(3) The polished disc sample was cut into two semidiscs, and then the vertical end of the semicircle was polished using a grinder to be perpendicular to the upper and lower ends.

(4) The thickness of the prefabricated crack was approximately $0.5 \mathrm{~mm}$; a customized wire-cutting system was used to make the prefabricated crack tip of the semidisc specimen. To refine the treatment, a cutting wire diameter of $0.25 \mathrm{~mm}$ was used.

To study the size effect of the NSCB specimen and its crack length, the radius $R$ was set to $25 \mathrm{~mm}, 37.5 \mathrm{~mm}$, $50 \mathrm{~mm}$, and $75 \mathrm{~mm}$. The ratio of the crack length to the specimen radius ratio $a / R$ was $0.4 \sim 0.6$ within a total of 36 NSCB specimens. The sizes of the specimens are shown in Table 1. 




(a)



(b)

FIgURE 1: Loading diagram of the NSCB test specimen. (a) Diagram of test loading. (b) Sample profile.

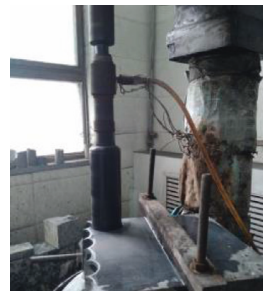

(a)

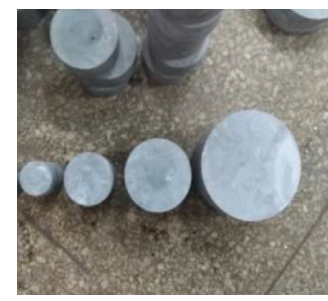

(b)

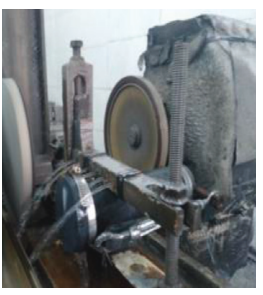

(c)

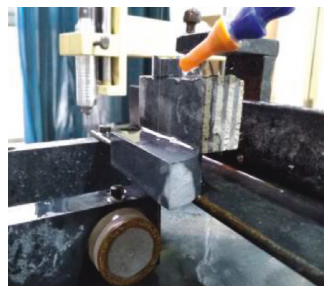

(d)

Figure 2: Sample preparation process. (a) Drilling the rock. (b) Creating the discs. (c) Grinding the rock face. (d) Making the artificial seam.

TABle 1: Geometric dimensions of the samples.

\begin{tabular}{|c|c|c|c|c|}
\hline Sample number & $\begin{array}{l}\text { Sample radius, } \\
R(\mathrm{~mm})\end{array}$ & $\begin{array}{l}\text { Sample thickness, } \\
B(\mathrm{~mm})\end{array}$ & $\begin{array}{l}\text { Length of the prefabricated } \\
\text { crack, } a(\mathrm{~mm})\end{array}$ & Dimensionless length of the prefabricated $\operatorname{crack} \alpha$ \\
\hline NSCB25-1-1 & 24.86 & 14.82 & 9.21 & 0.37 \\
\hline NSCB25-1-2 & 24.01 & 14.86 & 9.05 & 0.38 \\
\hline NSCB25-1-3 & 24.44 & 14.99 & 9.78 & 0.40 \\
\hline NSCB25-2-1 & 24.15 & 14.98 & 12.22 & 0.51 \\
\hline NSCB25-2-2 & 24.72 & 14.86 & 12.24 & 0.50 \\
\hline NSCB25-2-3 & 24.55 & 14.97 & 12.23 & 0.50 \\
\hline NSCB25-3-1 & 23.94 & 14.82 & 14.02 & 0.59 \\
\hline NSCB25-3-2 & 24.02 & 14.98 & 14.01 & 0.58 \\
\hline NSCB25-3-3 & 23.98 & 14.86 & 14.02 & 0.58 \\
\hline NSCB37.5-1-1 & 37.52 & 22.77 & 14.56 & 0.39 \\
\hline NSCB37.5-1-2 & 37.96 & 22.25 & 15.98 & 0.42 \\
\hline NSCB37.5-1-3 & 37.34 & 22.86 & 14.53 & 0.39 \\
\hline NSCB37.5-2-1 & 36.94 & 22.87 & 18.16 & 0.49 \\
\hline NSCB37.5-2-2 & 37.11 & 22.54 & 18.32 & 0.49 \\
\hline NSCB37.5-2-3 & 37.96 & 22.76 & 18.43 & 0.49 \\
\hline NSCB37.5-3-1 & 36.44 & 22.96 & 21.42 & 0.59 \\
\hline NSCB37.5-3-2 & 36.33 & 22.64 & 21.98 & 0.61 \\
\hline NSCB37.5-3-3 & 36.45 & 22.72 & 22.04 & 0.60 \\
\hline NSCB50-1-1 & 48.42 & 29.98 & 19.9 & 0.41 \\
\hline NSCB50-1-2 & 48.53 & 29.98 & 19.9 & 0.41 \\
\hline NSCB50-1-3 & 48.87 & 29.99 & 19.9 & 0.41 \\
\hline NSCB50-2-1 & 48.2 & 29.96 & 23.88 & 0.50 \\
\hline NSCB50-2-2 & 48.89 & 29.89 & 24.05 & 0.49 \\
\hline NSCB50-2-3 & 48.89 & 29.89 & 24.09 & 0.49 \\
\hline
\end{tabular}


TABle 1: Continued.

\begin{tabular}{|c|c|c|c|c|}
\hline Sample number & $\begin{array}{c}\text { Sample radius, } \\
R(\mathrm{~mm}) \\
\end{array}$ & $\begin{array}{l}\text { Sample thickness, } \\
B(\mathrm{~mm}) \\
\end{array}$ & $\begin{array}{l}\text { Length of the prefabricated } \\
\text { crack, } a(\mathrm{~mm})\end{array}$ & Dimensionless length of the prefabricated crack $\alpha$ \\
\hline NSCB50-3-1 & 49.01 & 29.99 & 29.36 & 0.60 \\
\hline NSCB50-3-2 & 48.24 & 29.82 & 28.89 & 0.60 \\
\hline NSCB50-3-3 & 49.12 & 29.99 & 28.89 & 0.59 \\
\hline NSCB75-1-1 & 73.03 & 45.01 & 29.23 & 0.40 \\
\hline NSCB75-1-2 & 73.99 & 49.87 & 29.95 & 0.40 \\
\hline NSCB75-1-3 & 72.58 & 44.79 & 29.01 & 0.40 \\
\hline NSCB75-2-1 & 74.98 & 44.87 & 37.05 & 0.49 \\
\hline NSCB75-2-2 & 74.01 & 45.01 & 37.95 & 0.51 \\
\hline NSCB75-2-3 & 74.33 & 44.89 & 37.96 & 0.51 \\
\hline NSCB75-3-1 & 74.05 & 44.82 & 45.03 & 0.61 \\
\hline NSCB75-3-2 & 74.89 & 45.12 & 45.22 & 0.60 \\
\hline NSCB75-3-3 & 74.11 & 44.53 & 44.53 & 0.60 \\
\hline
\end{tabular}

2.3. Experimental Equipment and Procedures. The threepoint bending fracture test was performed in an RMT-150B (Wuhan Institute of Geotechnical Mechanics, Chinese Academy of Sciences, Wuhan city, Hubei Province, China) testing machine configured as shown in Figure 3. The maximum vertical load of the test machine is $1000 \mathrm{kN}$, and the maximum compression deformation is $20 \mathrm{~mm}$; this configuration meets the requirements for test range and accuracy. This machine is also capable of recording test results (including loads, displacements, and elongations) using a data logger, and the curve is recorded and output by the RMT-150B control software on the computer.

To obtain a more stable load-displacement curve and straight crack propagation path, the displacement-loading control was used and its loading rate was $0.0002 \mathrm{~mm} / \mathrm{s}$.

\section{Derivative Equation of the NSCB Specimen Based on the Dimensional Energy Release Rate Theory}

Bažant provided an equation for calculating the nominal strength of $\sigma_{\mathrm{n}}$ a three-point bend beam specimen [11]:

$$
\sigma_{\mathrm{n}}=c_{\mathrm{n}} \frac{P_{\mu}}{b d}
$$

where $P_{\mu}$ is the maximum load, $c_{\mathrm{n}}$ is the intrinsic coefficient of the specimen, $b$ is the thickness of the specimen, and $d$ is the characteristic size (height or depth) of the specimen. For the NSCB specimen, its characteristic size is equal to $R . E^{\prime}=$ $E$ (plane-stress state) or $E^{\prime}=E /\left(1-v^{2}\right)$ (plane-strain state), where $E$ represents Young's modulus and $v$ represents Poisson's ratio. The strain energy $U$ is given by

$$
U=\left(\frac{\sigma^{2}}{2 E^{\prime}}\right) V f(\alpha)
$$

where $\sigma=c_{\mathrm{n}} P / b d$, where $P$ is the load applied on the specimen; $V=b d^{2}$ represents the volume of the specimen; $f(\alpha)$ is a function related to the length of the crack; and $\alpha=a / d=a / R$ (for NSCB specimen, its characteristic size $d$ is equal to its radius $R$ ) indicates the dimensionless crack

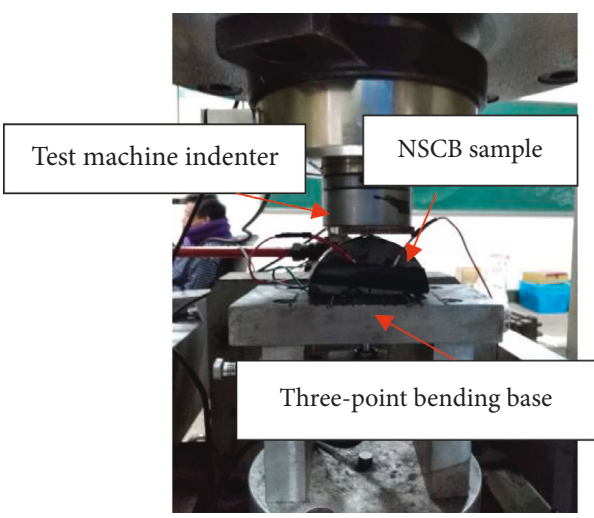

Figure 3: Fracture test diagram of the NSCB specimen.

length ( $a$ represents the crack length of the specimen). Therefore, the energy release rate $G$ is

$$
G=-\frac{(\partial U / \partial a)}{b}=-\frac{(\partial U / \partial \alpha)}{b d}=-\left(\frac{\sigma^{2}}{2 E^{\prime}}\right) f^{\prime}(\alpha) d
$$

That is,

$$
\begin{aligned}
G & =\frac{P^{2} g(\alpha)}{E^{\prime} b^{2} d}, \\
K_{\mathrm{I}} & =\sqrt{G E^{\prime}}=\frac{P k(\alpha)}{b \sqrt{d}},
\end{aligned}
$$

where $f^{\prime}(\alpha)=\partial f(\alpha) / \partial \alpha, g(\alpha)=-f^{\prime}(\alpha) c_{\mathrm{n}}^{2} / 2$, and $k(\alpha)=$ $\sqrt{g(\alpha)} . g(\alpha)$ represents the geometry function of the specimen, and $k(\alpha)$ is a function associated with the sample configuration and the loading method. $g(\alpha)$, an important parameter in studying the scale law of fracture toughness, depends on the geometry of the specimen and represents a dimensionless energy release rate function independent of the size. The geometrical function of the NSCB sample $g_{*}(\alpha)$ is derived below.

Equation (1) describes the fracture toughness of the NSCB specimen. The relationship between the fracture toughness $K_{\text {Ic }}$ and the energy release rate $G_{*}$ of the NSCB sample satisfies equation (7) under the condition of the linear elasticity. 


$$
K_{\mathrm{Ic}}^{2}=G_{*} E^{\prime}
$$

The NSCB sample energy release rate $G_{*}$ can be obtained using equations (1) and (7):

$$
G_{*}=\frac{P_{\max }^{2} \pi a}{4 R^{2} B^{2} E^{\prime}} Y^{2} .
$$

For NSCB specimens, the characteristic size is the radius $R$ of the specimen, which corresponds to $d$ in equation (6), and $B$ is the thickness, which corresponds to $b$ in equation (6). For a certain specimen configuration, the energy release rate is a fixed value; therefore, $G=G_{*}$, and the expression of the dimensionless energy release rate of the NSCB sample can be obtained as follows:

$$
g_{*}(\alpha)=\frac{\pi}{4} \alpha Y^{2}
$$

where $\alpha=a / d=a / R$ represents the dimensionless crack length of the NSCB specimen (where $a$ again represents the crack length of the specimen) and $Y$ represents the dimensionless stress intensity factor, which is calculated in equation (2). Bažant et al. [10, 11] introduced the fracture toughness $K_{\mathrm{Ic}}^{\mathrm{m}}$ and the effective fracture zone length $c_{\mathrm{f}}$ of the infinitely large specimen by introducing two material fracture parameters on the basis of the blunt fracture zone model. The following law of the scale effect of fracture toughness was proposed:

$$
K_{\mathrm{Ic}}=\frac{K_{\mathrm{Ic}}^{\mathrm{m}}}{\sqrt{1+\left(g_{*}^{\prime}(\alpha) / g_{*}(\alpha) d\right)} c_{\mathrm{f}}},
$$

where $K_{\mathrm{Ic}}$ represents the test value of the fracture toughness, which is calculated according to the linear elastic fracture mechanics equation with the initial crack length $a$ combined with the maximum load $P_{\max } ; K_{\mathrm{Ic}}^{\mathrm{m}}$ represents the true fracture toughness value of the rock material; $c_{\mathrm{f}}$ represents the length of the fracture process zone; $g_{*}(\alpha)$ represents the dimensionless energy release rate; and $g_{*}^{\prime}(\alpha)$ is the derivative of $g_{*}(\alpha)$ to $\alpha$; then, we substitute $\alpha$ for $g_{*}^{\prime}\left(\alpha_{0}\right)$. When the specimen is infinite, the fracture process area can be fully developed without the boundary conditions of the specimen; thus, $c_{\mathrm{f}}$ is a material constant. In addition, the length of the initial fracture length $\alpha$ is sufficiently long so that the length of the fracture process zone can be ignored and the linear-elastic fracture mechanics is still applicable. $K_{\mathrm{Ic}}^{\mathrm{m}}$ is the material constant. Therefore, as long as $K_{\mathrm{Ic}}^{\mathrm{m}}$ and $c_{\mathrm{f}}$ can be determined and substituted into the equation (10), the scale law equation of a given geometry specimen can be obtained and used to predict the fracture toughness value of larger specimens.

The International Union of Laboratories and Experts in Construction Materials, Systems, and Structures (RILEM) have provided the following solution procedure [28]:

(a) The corrected maximum loads, $P_{1}^{0}, \ldots, P_{n}^{0}$, which take the weight of the specimen into account, must be calculated:

$$
P_{j}^{0}=P_{j}+\frac{1}{2} W_{j}, \quad(j=1,2, \ldots, n),
$$

where $W_{j}$ is the mass of the specimen and $n$ is the number of tests conducted.

(b) Perform linear regression, considering the plot of the ordinates $Y_{j}$ against the abscissa $X_{j}$, where

$$
\begin{aligned}
& Y_{j}=\left(\frac{b d_{j}}{P_{j}^{0}}\right)^{2}, \\
& X_{j}=d_{j} .
\end{aligned}
$$

Determine the slope and intercept of the regression line $Y=A X+C$ :

$$
\begin{aligned}
A & =\frac{\sum_{j}\left(X_{j}-\bar{X}\right)\left(Y_{j}-\bar{Y}\right)}{\sum_{j}\left(X_{j}-\bar{X}\right)^{2}}, \\
C & =\bar{Y}-A \bar{X},
\end{aligned}
$$

where

$$
\begin{aligned}
& \bar{X}=\frac{1}{n} \sum_{j} X_{j}, \\
& \bar{Y}=\frac{1}{n} \sum_{j} Y_{j} .
\end{aligned}
$$

(c) Calculate the dimensionless energy release rate $g_{*}(\alpha)$ using equation (9)

(d) Calculate the fracture energy of the material $G_{\mathrm{f}}$ :

$$
G_{\mathrm{f}}=\frac{g(\alpha)}{E_{\mathrm{c}} A} .
$$

The value of $K_{\mathrm{Ic}}^{\mathrm{m}}$ can be obtained from equation (7), which is the relationship between the nondimensional energy release rate and the fracture toughness. The length of the fracture zone $c_{\mathrm{f}}$ can also be obtained from the following equation:

$$
c_{\mathrm{f}}=\frac{g_{*}(\alpha)}{g_{*}^{\prime}(\alpha)}\left(\frac{C}{A}\right) \text {. }
$$

The scaling law of NSCB sample fracture toughness can be obtained by obtaining $c_{\mathrm{f}}$ and $K_{\mathrm{Ic}}^{\mathrm{m}}$ using equation (10).

\section{Test Results and Size Effect Analysis}

4.1. Test Results of Fracture Toughness. The three-point bending fracture test of the NSCB specimen was performed on an RMT-150B test machine; the maximum load of each specimen $P_{\mu}$ was obtained, and the test value of NSCB sample fracture toughness $K_{\text {Ic }}$ was obtained by substituting $P_{\mu}$ into equation (1), as listed in Table 2.

Figure 4 shows that the fracture toughness of the NSCB specimen changes with increasing specimen radius under three kinds of dimensionless crack length. 
TABLE 2: Analysis data of the NSCB sample.

\begin{tabular}{|c|c|c|c|c|}
\hline $\begin{array}{l}\text { Sample } \\
\text { number }\end{array}$ & $\begin{array}{l}\text { Maximum load, } P_{\mu} \\
(\mathrm{N})\end{array}$ & $\begin{array}{l}\text { Test value of fracture toughness, } K_{\mathrm{Ic}} \\
\qquad\left(\mathrm{MPa} \cdot \mathrm{m}^{1 / 2}\right)\end{array}$ & $\begin{array}{l}\text { True value of fracture } \\
\text { toughness } K_{\mathrm{Ic}}^{\mathrm{m}}\end{array}$ & $\begin{array}{l}\text { Length of the fracture zone, } C_{\mathrm{f}} \\
\qquad(\mathrm{mm})\end{array}$ \\
\hline NSCB25-1-1 & 1366 & 1.123 & 1.203 & 1.911 \\
\hline NSCB25-1-2 & 1358 & 1.155 & 1.226 & 1.887 \\
\hline NSCB25-1-3 & 1052 & 0.944 & 1.316 & 1.812 \\
\hline NSCB25-2-1 & 762 & 0.978 & 2.112 & 18.445 \\
\hline NSCB25-2-2 & 492 & 0.606 & 2.034 & 18.524 \\
\hline NSCB25-2-3 & 570 & 0.706 & 2.056 & 18.500 \\
\hline NSCB25-3-1 & 400 & 0.686 & 1.567 & 10.378 \\
\hline NSCB25-3-2 & 402 & 0.676 & 1.555 & 10.373 \\
\hline NSCB25-3-3 & 476 & 0.811 & 1.562 & 10.376 \\
\hline $\begin{array}{l}\text { NSCB37.5- } \\
1-1\end{array}$ & 2788 & 1.280 & 1.268 & 1.849 \\
\hline $\begin{array}{l}\text { NSCB37.5- } \\
1-2\end{array}$ & 2062 & 1.068 & 1.406 & 1.758 \\
\hline $\begin{array}{l}\text { NSCB37.5- } \\
1-3\end{array}$ & 2402 & 1.105 & 1.272 & 1.845 \\
\hline $\begin{array}{l}\text { NSCB37.5- } \\
2-1\end{array}$ & 1646 & 1.064 & 2.010 & 18.555 \\
\hline $\begin{array}{l}\text { NSCB37.5- } \\
2-2\end{array}$ & 1618 & 1.067 & 2.024 & 18.537 \\
\hline $\begin{array}{l}\text { NSCB37.5- } \\
2-3\end{array}$ & 1864 & 1.170 & 1.969 & 18.612 \\
\hline $\begin{array}{l}\text { NSCB37.5- } \\
3-1\end{array}$ & 1206 & 1.091 & 1.579 & 10.383 \\
\hline $\begin{array}{l}\text { NSCB37.5- } \\
3-2\end{array}$ & 1137 & 1.108 & 1.676 & 10.431 \\
\hline $\begin{array}{l}\text { NSCB37.5- } \\
3-3\end{array}$ & 1004 & 0.972 & 1.674 & 10.430 \\
\hline NSCB50-1-1 & 4174 & 1.376 & 1.362 & 1.782 \\
\hline NSCB50-1-2 & 3146 & 1.033 & 1.358 & 1.785 \\
\hline NSCB50-1-3 & 4130 & 1.339 & 1.346 & 1.792 \\
\hline NSCB50-2-1 & 2770 & 1.213 & 2.036 & 18.522 \\
\hline NSCB50-2-2 & 2876 & 1.238 & 2.012 & 18.552 \\
\hline NSCB50-2-3 & 2550 & 1.101 & 2.018 & 18.545 \\
\hline NSCB50-3-1 & 1530 & 0.950 & 1.642 & 10.413 \\
\hline NSCB50-3-2 & 1820 & 1.144 & 1.641 & 10.412 \\
\hline NSCB50-3-3 & 1860 & 1.111 & 1.581 & 10.384 \\
\hline NSCB75-1-1 & 7300 & 1.262 & 1.317 & 1.811 \\
\hline NSCB75-1-2 & 7124 & 1.120 & 1.336 & 1.799 \\
\hline NSCB75-1-3 & 7942 & 1.382 & 1.315 & 1.813 \\
\hline NSCB75-2-1 & 4592 & 1.072 & 2.027 & 18.533 \\
\hline NSCB75-2-2 & 5432 & 1.356 & 2.162 & 18.406 \\
\hline NSCB75-2-3 & 4936 & 1.224 & 2.146 & 18.417 \\
\hline NSCB75-3-1 & 3182 & 1.109 & 1.694 & 10.441 \\
\hline NSCB75-3-2 & 3684 & 1.250 & 1.669 & 10.427 \\
\hline NSCB75-3-3 & 3304 & 1.130 & 1.652 & 10.418 \\
\hline
\end{tabular}

(1) The fracture toughness values increase with increasing specimen radius, showing a prominent size effect. When $\alpha=0.4$ and the sample radius increases from $25 \mathrm{~mm}$ to $75 \mathrm{~mm}$, the average value of fracture toughness increases from $1.074 \mathrm{MPa} \cdot \mathrm{m}^{1 / 2}$ to $1.255 \mathrm{MPa} \cdot \mathrm{m}^{1 / 2}$, an increase of $16.9 \%$. When $\alpha=0.5$ and the sample radius increases from $25 \mathrm{~mm}$ to $75 \mathrm{~mm}$, the average value of fracture toughness increases from $0.763 \mathrm{MPa} \cdot \mathrm{m}^{1 / 2}$ to $1.217 \mathrm{MPa} \cdot \mathrm{m}^{1 / 2}$, an increase of $59.5 \%$. When $\alpha=0.6$ and sample radius increases from $25 \mathrm{~mm}$ to $75 \mathrm{~mm}$, the average value of fracture toughness increases from $0.724 \mathrm{MPa} \cdot \mathrm{m}^{1 / 2}$ to
$1.163 \mathrm{MPa} \cdot \mathrm{m}^{1 / 2}$, an increase of $60.6 \%$. Thus, the sample radius has a significant influence on the fracture toughness of NSCB, and the effect increases with increasing crack length.

(2) The length of crack has a strong influence on fracture toughness, and as the length of the crack increases, the test value of fracture toughness of NSCB decreases continuously. When the sample radius is $25 \mathrm{~mm}$ and the dimensionless crack length increases from $\alpha=0.4$ to $\alpha=0.6$, the average fracture toughness decreases from $1.074 \mathrm{MPa} \cdot \mathrm{m}^{1 / 2}$ to 0.724 $\mathrm{MPa} \cdot \mathrm{m}^{1 / 2}$, a reduction of $32.6 \%$. When the sample 


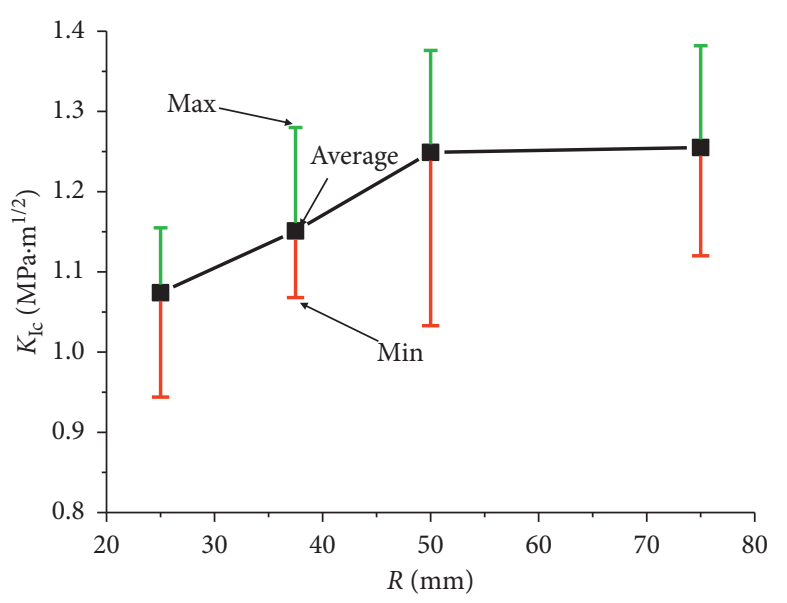

(a)

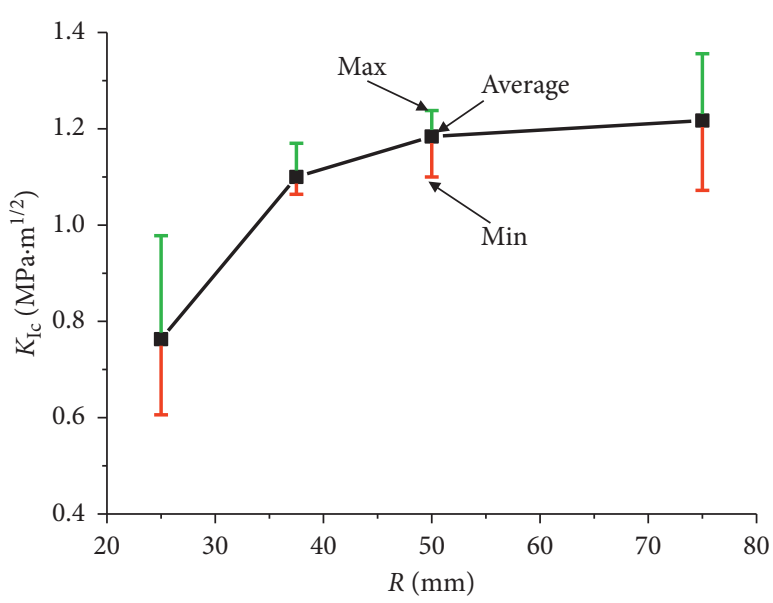

(b)

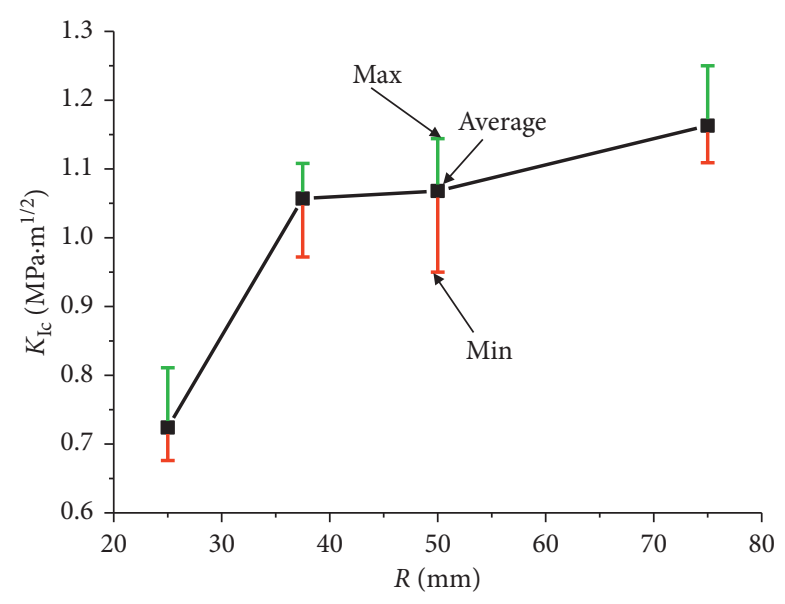

(c)

Figure 4: Fracture toughness test value dependence on the sample radius. (a) $\alpha=0.4$. (b) $\alpha=0.5$. (c) $\alpha=0.6$.

radius is $37.5 \mathrm{~mm}$ and the dimensionless crack length increases from $\alpha=0.4$ to $\alpha=0.6$, the average fracture toughness decreases from $1.151 \mathrm{MPa} \cdot \mathrm{m}^{1 / 2}$ to $1.057 \mathrm{MPa} \cdot \mathrm{m}^{1 / 2}$, a reduction of $8.17 \%$. When the sample radius is $50 \mathrm{~mm}$ and the dimensionless crack length increases from $\alpha=0.4$ to $\alpha=0.6$, the average fracture toughness decreases from $1.249 \mathrm{MPa} \cdot \mathrm{m}^{1 / 2}$ to $1.068 \mathrm{MPa} \cdot \mathrm{m}^{1 / 2}$, a reduction of $14.5 \%$. When the sample radius is $75 \mathrm{~mm}$ and the dimensionless crack length increases from $\alpha=0.4$ to $\alpha=0.6$, the average fracture toughness decreases from $1.255 \mathrm{MPa} \cdot \mathrm{m}^{1 / 2}$ to $1.163 \mathrm{MPa} \cdot \mathrm{m}^{1 / 2}$, a reduction of $7.3 \%$. In general, the influence of the length of fracture on the specimen with different sizes is different; the strongest influence occurs with the specimen with a radius of $25 \mathrm{~mm}$, and the smallest influence occurs with the specimen with a radius of $75 \mathrm{~mm}$.

4.2. Size Effect Analysis of the Fracture Toughness Test Value. In the RILEM recommendation method, the thickness, radius, and maximum load of the specimens are directly applied to the equation of the coordinate solution of the regression coordinate point. The ordinate value of the regression data point is obtained, and the radius of the sample is used as the horizontal coordinate. According to the method recommended by RILEM, linear regression is obtained, and the regression curve is shown in Figure 5.

The slope $A$ and intercept $C$ of the regression line can be obtained from the linear regression equation obtained from Figure 5. The fracture energy of the NSCB specimen is obtained by substituting the slope $A$ into equation (15), and the true fracture toughness $K_{\mathrm{Ic}}^{\mathrm{m}}$ of each specimen can be obtained from equation (7). Finally, the slope $A$ and intercept $C$ are substituted into equation (16) to obtain the fracture toughness process area $c_{\mathrm{f}} . K_{\mathrm{Ic}}^{\mathrm{m}}$ and $c_{\mathrm{f}}$ are listed in Table 2.

We average the true fracture toughness values of the samples with a radius of $25 \mathrm{~mm}, 37.5 \mathrm{~mm}$, and $50 \mathrm{~mm}$ (the true value of the fracture toughness of the NSCB specimen with a radius of $75 \mathrm{~mm}$ is used as the detection value); next, the average value of fracture toughness and the length of fracture process zone of NSCB specimens are obtained under the condition of each fracture length: (1) when $\alpha=0.4$, $K_{\mathrm{Ic}}^{\mathrm{m}}=1.306 \mathrm{MPa} \cdot \mathrm{m}^{1 / 2}$ and $c_{\mathrm{f}}=1.825 \mathrm{~mm}$; (2) when $\alpha=0.5$, $K_{\mathrm{Ic}}^{\mathrm{m}}=2.03 \mathrm{MPa} \cdot \mathrm{m}^{1 / 2}$ and $c_{\mathrm{f}}=18.532 \mathrm{~mm}$; and (3) when 


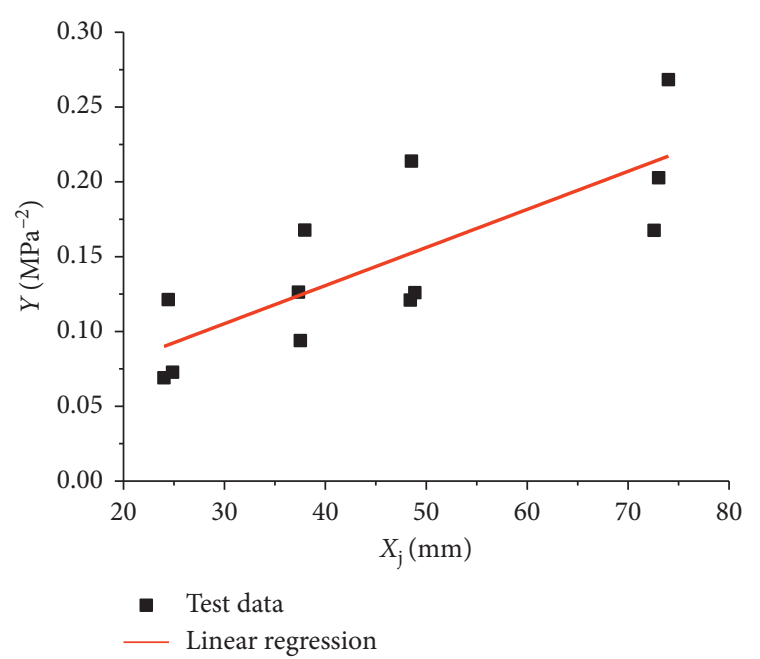

(a)

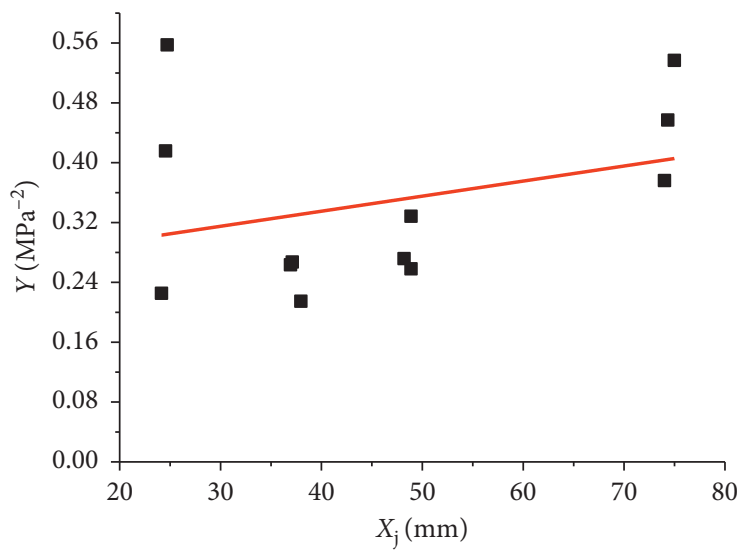

- Test data

— Linear regression

(b)

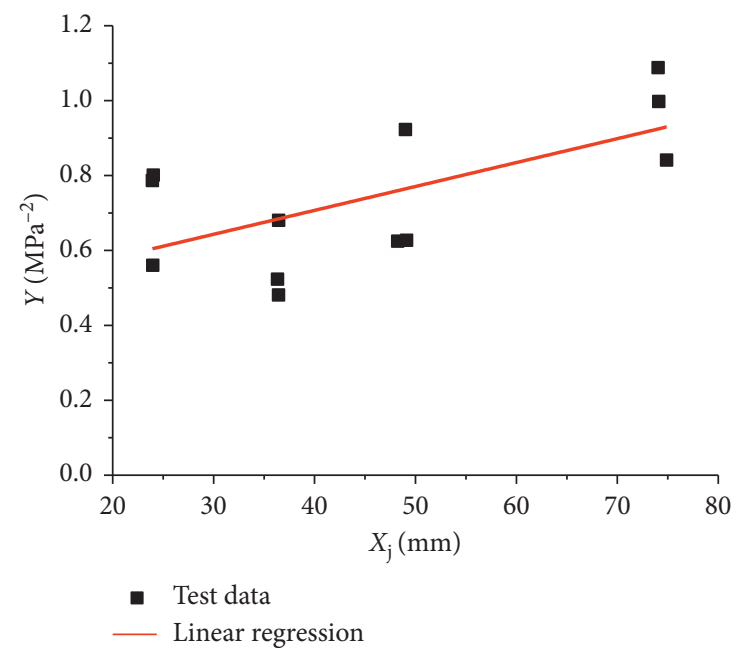

(c)

Figure 5: Test regression curve. (a) $\alpha=0.4$. (b) $\alpha=0.5$. (c) $\alpha=0.6$.

$\alpha=0.6, \quad K_{\mathrm{Ic}}^{\mathrm{m}}=1.609 \mathrm{MPa} \cdot \mathrm{m}^{1 / 2}$ and $c_{\mathrm{f}}=10.398 \mathrm{~mm} . \quad \mathrm{By}$ substituting the values of $K_{\mathrm{Ic}}^{\mathrm{m}}$ and $c_{\mathrm{f}}$ into equation (10), the equation of the Bažant scaling law under three types of crack lengths is obtained:

$$
\begin{array}{ll}
K_{\mathrm{Ic}}=\frac{1.306}{\sqrt{1+\left(g^{\prime}(\alpha) / g(\alpha) d\right)} 1.825}, & \alpha=0.4, \\
K_{\mathrm{Ic}}=\frac{2.03}{\sqrt{1+\left(g^{\prime}(\alpha) / g(\alpha) d\right)} 18.532}, & \alpha=0.5, \\
K_{\mathrm{Ic}}=\frac{1.609}{\sqrt{1+\left(g^{\prime}(\alpha) / g(\alpha) d\right)} 10.398}, & \alpha=0.6 .
\end{array}
$$

From the previous analysis, it is known that the fracture toughness obtained by the maximum load and the initial fracture length has a prominent size effect. As the sample radius scales as $1: 1.5: 2: 3$, for the dimensionless prefabricated crack lengths $\alpha=0.4, \alpha=0.5$, and $\alpha=0.6$, the fracture toughness test values increase as $1: 1.07: 1.16: 1.17$, $1: 1.44: 1.55: 1.6$, and $1: 1.46: 1.48: 1.61$, respectively. Using the RILEM recommendation method, the NSCB sample Bažant scale law equation for different fracture lengths is obtained, as shown in equation (17). Equation (17) can reflect the size effect of NSCB sample fracture toughness, as shown in Figure 6.

Equation (17) is determined by the average value of the true value of fracture toughness of NSCB specimens with specimen radius values $R$ of $25 \mathrm{~mm}, 37.5 \mathrm{~mm}$, and $50 \mathrm{~mm}$. Using the NSCB fracture toughness test value of radius of $75 \mathrm{~mm}$ as the detection value, the prediction accuracy of the equation of scale law is determined; the results obtained are shown in Table 3. The dimensionless crack length $\alpha$ is in the range of $0.4-0.6$, and with increasing $\alpha$, the prediction accuracy of equation (17) is continually improved. The maximum error is less than $3 \%$. Therefore, the Bažant equation can correctly reflect the change of the size effect of the fracture toughness of NSCB specimens and offer high accuracy in predicting the fracture toughness of large specimens. 




(a)

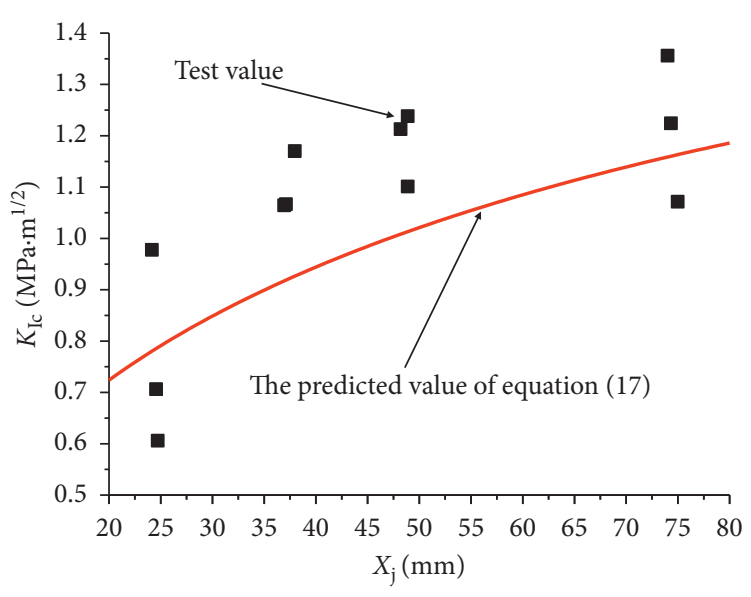

(b)



(c)

Figure 6: NSCB scale law equation curves and test values. (a) $\alpha=0.4$. (b) $\alpha=0.5$. (c) $\alpha=0.6$.

TABLE 3: Analysis of the equation predictions.

Sample number Sample radius $(\mathrm{mm})$ Crack length $(\alpha)$ Average test value $\left(\mathrm{MPa} \cdot \mathrm{m}^{1 / 2}\right)$ Predicted value $\left(\mathrm{MPa} \cdot \mathrm{m}^{1 / 2}\right) \quad$ Relative error $(\%)$

\begin{tabular}{llllcc}
\hline NSCB75-1-1-3 & 75 & 0.4 & 1.255 & 1.218 & 2.94 \\
NSCB75-2-1-3 & 75 & 0.5 & 1.217 & 1.237 & 1.6 \\
NSCB75-3-1-3 & 75 & 0.6 & 1.163 & 1.15 & 1.11 \\
\hline
\end{tabular}

\section{Discussion of the Correlation between the Fracture Toughness and Other Parameters}

For the Bažant scaling law shown in equation (17), as the sample size approaches infinity $(R \longrightarrow \infty)$, fracture toughness values of finite samples approach the real fracture toughness, i.e., $K_{\mathrm{Ic}}$ approaches $K_{\mathrm{Ic}}^{\mathrm{m}}$.

Certain correlations exist between the physical and mechanical parameters of rock. A large number of studies have confirmed that the fracture toughness $\left(K_{\mathrm{Ic}}^{\mathrm{m}}\right)$, as a rock mechanical parameter, is related to the compressive strength $\left(\sigma_{\mathrm{c}}\right)$, density $(\rho)$, and $P$-wave velocity $\left(V_{\mathrm{p}}\right)$, among other properties. Therefore, other parameters of rock can be used to estimate the value of $K_{\mathrm{Ic}}^{\mathrm{m}}$ [29]. A previous report [29] summarized the empirical equations between $K_{\mathrm{Ic}}^{\mathrm{m}}$ and $\sigma_{\mathrm{c}}, \rho$, and $V_{\mathrm{p}}$, as given by the following equation:

$$
\left.\begin{array}{l}
K_{\mathrm{Ic}}^{\mathrm{m}}=0.0044 \sigma_{\mathrm{c}}+1.04, \\
K_{\mathrm{Ic}}^{\mathrm{m}}=3.21 \rho-6.95, \\
K_{\mathrm{Ic}}^{\mathrm{m}}=3.5 \times 10^{-4} V_{\mathrm{p}}-0.18 .
\end{array}\right\}
$$

The true fracture toughness of limestone used in this test can be estimated by substituting the parameters of limestone measured in equation (18). The fracture toughness values of three types of NSCB specimens with different fracture lengths were obtained by assuming that the specimen radius was infinite, and the true values of fracture toughness were obtained by averaging. The measured average values of $\sigma_{\mathrm{c}}, \rho$, and $V_{\mathrm{p}}$ along with the estimated results are listed in Table 4. Note that to predict the fracture toughness of the NSCB specimen of radius of $75 \mathrm{~mm}$, the equation of the Bažant scaling law obtained in the previous section is $K_{\mathrm{Ic}}^{\mathrm{m}}$, and the 
TABLE 4: Comparison of the results of this study with the estimation results.

\begin{tabular}{lccccc}
\hline & Test value & True value & Estimation result $\left(\sigma_{\mathrm{c}}\right)$ & Estimation result $(\rho)$ & Estimation result $\left(V_{\mathrm{p}}\right)$ \\
\hline Fracture toughness $\left(\mathrm{MPa} \cdot \mathrm{m}^{1 / 2}\right)$ & 1.084 & 1.662 & 1.784 & 1.717 & 1.804 \\
Relative error $(\%)$ & 0 & 53.32 & 64.57 & 58.39 & 66.42 \\
\hline
\end{tabular}

mean value of the NSCB samples with radius values of $25 \mathrm{~mm}, 37.5 \mathrm{~mm}$, and $50 \mathrm{~mm}$ are substituted into equation (10). Here, we take the four average fracture toughness values for sample radius values from $25 \mathrm{~mm}$ to $75 \mathrm{~mm}$ to represent $K_{\mathrm{Ic}}^{\mathrm{m}}$ in the Bažant scale equation using the same method and calculate the value of $K_{\mathrm{Ic}}^{\mathrm{m}}$; the results are shown in Table 4.

According to Table 4, a large difference exists between the fracture toughness test results obtained by the initial crack length and the maximum load and those that can be obtained by other methods, and the maximum error is $66.42 \%$, which shows that one cannot simply ignore the influence of the size effect when conducting rock fracture toughness tests. In addition, the true fracture toughness value of limestone calculated using the Bažant equation is close to that obtained using other mechanical parameters for the same limestone, and the relative errors are less than $10 \%$. The cause of this relative error may be related to the specimen configuration and the rock sample characteristics.

\section{Conclusion}

The three-point bending fracture test was conducted with an NSCB sample as recommended by the International Society of Rock Mechanics, and the influence of the sample size and crack length on the fracture toughness test value was analyzed. The main conclusions are as follows:

(1) For the same crack length, the fracture toughness has a prominent size effect. The empirical fracture toughness increases with increasing sample radius, with the test value of the fracture toughness increasing 1.6 times when the radius increases from $25 \mathrm{~mm}$ to $75 \mathrm{~mm}$.

(2) For a fixed sample size, an increase in crack length decreases the fracture toughness test value, and the maximum decrease is as high as $32.6 \%$. The decrease varies with the sample radius; a sample disk radius of $25 \mathrm{~mm}$ has the greatest impact, and a sample disk radius of $75 \mathrm{~mm}$ has the least influence;

(3) The fracture toughness measured by the initial crack length and maximum load is lower than the true value by $53.32 \%$. The RILEM recommendation method is used to obtain the NSCB-sample Bažant scaling law equation, which correctly reflects the NSCB specimen size effect of the fracture toughness; for large specimens, the fracture toughness is predicted with high precision, with an error of less than $3 \%$.

\section{Data Availability}

Data supporting this research article are available from the corresponding author.

\section{Conflicts of Interest}

The authors declare that they have no conflicts of interest.

\section{Acknowledgments}

This study was financially supported by the National Key Research and Development Program of China (grant no. 2016YFC0600701), the National Natural Science Foundation of China (grant nos. 51674101 and 51674170), and the Key Laboratory Open Project Fund in Henan Province (grant no. S201605).

\section{References}

[1] M.-D. Wei, F. Dai, Y. Liu, N.-W. Xu, and T. Zhao, "An experimental and theoretical comparison of CCNBD and CCNSCB specimens for determining mode I fracture toughness of rocks," Fatigue \& Fracture of Engineering $\mathrm{Ma}$ terials \& Structures, vol. 41, no. 5, pp. 1002-1018, 2018.

[2] F. Feng, C. G. Wei, and Q. Z. Wang, "Size effect for rock dynamic fracture toughness tested with cracked straight through flattened Brazilian disc," Engineering Mechanics, vol. 26, no. 4, pp. 167-173, 2009, in Chinese.

[3] S. Zhang, Q. Z. Wang, and Y. L. Liang, "Research on influence of crack length on test values of rock dynamic fracture toughness," Chinese Journal of Rock Mechanics and Engineering, vol. 28, no. 8, pp. 1691-1696, 2009, in Chinese.

[4] G. Q. Zhang, M. Chen, and X. Y. Yang, "Influence of fracture width on rock toughness measurement," Journal of the University of Petroleum, China, vol. 26, no. 6, pp. 42-45, 2002, in Chinese.

[5] C. Li, "A study of the effect of temperature on the fracture properties of rock materials," Journal of Nanjing Institute of Technology (Natural Science Edition), vol. 11, no. 4, pp. 39-46, 2013, in Chinese.

[6] J. Xu, S. M. Dong, and W. Hua, "Effect of confining pressure on stress intensity factors determined by cracked Brazilian disk," Rock and Soil Mechanics, vol. 36, no. 7, pp. 1959-1965, 2015, in Chinese.

[7] Q. Yin, H. W. Jing, H. J. Su et al., "Loading rate effect on fracture properties of granite after high temperature," Journal of China University of Mining \& Technology, vol. 44, no. 4, pp. 597-603, 2015, in Chinese.

[8] Y. Xu, F. Dai, N. W. Xu, and T. Zhao, "Numerical investigation of dynamic rock fracture toughness determination using a semi-circular bend specimen in split Hopkinson pressure bar testing," Rock Mechanics and Rock Engineering, vol. 49, no. 3, pp. 731-745, 2016.

[9] F. Dai, Y. Xu, T. Zhao, N.-W. Xu, and Y. Liu, "Loading-ratedependent progressive fracturing of cracked chevron-notched Brazilian disc specimens in split Hopkinson pressure bar tests," International Journal of Rock Mechanics and Mining Sciences, vol. 88, pp. 49-60, 2016.

[10] Z. P. Bažant, "Size effect," International Journal of Solids and Structures, vol. 37, pp. 69-80, 2000. 
[11] Z. P. Bažant and M. T. Kazemi, "Size dependence of concrete fracture energy determined by RILEM work-of-fracture method," International Journal of Fracture, vol. 51, pp. 121138, 1991.

[12] L. Z. Wu, X. M. Jia, and Q. Z. Wang, "A new stress intensity factor formula of cracked chevron notched Brazilian disc (CCNBD) and its application to analyzing size effect," Rock and Soil Mechanics, vol. 25, no. 2, pp. 233-237, 2004, in Chinese.

[13] S. Zhang, Q. Z. Wang, and H. P. Xie, "Size effect of rock dynamic fracture toughness," Explosion and Shock Waves, vol. 28, no. 6, pp. 544-551, 2008, in Chinese.

[14] M. Yu, W. C. Zhu, Y. J. Yu et al., "Numerical simulation for calculating the tensile strength and fracture toughness based on different grain sizes," Journal of Northeastern University (Natural Science), vol. 38, no. 6, pp. 864-868, 2017, in Chinese.

[15] A. Arslan and R. Ince, "The neural network approximation to the size effect in fracture of cementitious materials," Engineering Fracture Mechanics, vol. 54, no. 2, pp. 249-261, 1996.

[16] M. R. Ayatollahi and J. Akbardoost, "Size effects in mode II brittle fracture of rocks," Engineering Fracture Mechanics, vol. 112-113, pp. 165-180, 2013.

[17] L. N. Y. Wong and H. H. Einstein, "Crack coalescence in molded gypsum and carrara marble: part 2-microscopic observations and interpretation," Rock Mechanics and Rock Engineering, vol. 42, no. 3, pp. 513-545, 2009.

[18] L. N. Y. Wong and X.-P. Zhang, "Size effects on cracking behavior of flaw-containing specimens under compressive loading," Rock Mechanics and Rock Engineering, vol. 47, no. 5, pp. 1921-1930, 2014.

[19] M.-D. Wei, F. Dai, N.-W. Xu, and T. Zhao, "Stress intensity factors and fracture process zones of ISRM-suggested chevron notched specimens for mode I fracture toughness testing of rocks," Engineering Fracture Mechanics, vol. 168, pp. 174-189, 2016.

[20] F. Dai, M. D. Wei, N. W. Xu, Y. Ma, and D. S. Yang, "Numerical assessment of the progressive rock fracture mechanism of cracked chevron notched Brazilian disc specimens," Rock Mechanics and Rock Engineering, vol. 48, no. 2, pp. 463-479, 2015.

[21] M. R. M. Aliha and M. R. Ayatollahi, "Two-parameter fracture analysis of SCB rock specimen under mixed mode loading," Engineering Fracture Mechanics, vol. 103, pp. 115-123, 2013.

[22] M. R. Ayatollahi and M. R. M. Aliha, "Fracture toughness study for a brittle rock subjected to mixed mode I/II loading," International Journal of Rock Mechanics and Mining Sciences, vol. 44, no. 4, pp. 617-624, 2007.

[23] M.-D. Wei, F. Dai, N.-W. Xu, Y. Liu, and T. Zhao, "Fracture prediction of rocks under mode I and mode II loading using the generalized maximum tangential strain criterion," Engineering Fracture Mechanics, vol. 186, pp. 21-38, 2017.

[24] M.-D. Wei, F. Dai, J.-W. Zhou, Y. Liu, and J. Luo, "A further improved maximum tangential stress criterion for assessing mode I fracture of rocks considering non-singular stress terms of the Williams expansion," Rock Mechanics and Rock Engineering, vol. 51, no. 11, pp. 3471-3488, 2018.

[25] M. D. Kuruppu, Y. Obara, M. R. Ayatollahi, K. P. Chong, and T. Funatsu, "ISRM-suggested method for determining the mode I static fracture toughness using semi-circular bend specimen," Rock Mechanics and Rock Engineering, vol. 47, no. 1, pp. 267-274, 2014.

[26] M.-D. Wei, F. Dai, N.-W. Xu, T. Zhao, and Y. Liu, “An experimental and theoretical assessment of semi-circular bend specimens with chevron and straight-through notches for mode I fracture toughness testing of rocks," International Journal of Rock Mechanics and Mining Sciences, vol. 99, pp. 28-38, 2017.

[27] M. D. Wei, F. Dai, N. W. Xu, T. Zhao, and K. W. Xia, "Experimental and numerical study on the fracture process zone and fracture toughness determination for ISRM-suggested semi-circular bend rock specimen," Engineering Fracture Mechanics, vol. 154, pp. 43-56, 2016.

[28] S. P. Shah, "Size-effects methods for determining fracture energy and process zone size of concrete," Materials and Structures, vol. 23, no. 6, pp. 461-465, 1990.

[29] H. Bao, F. Q. Wu, and P. C. Xi, "Estimation of mode I fracture toughness of rock and its impact factors analysis," Journal of China Coal Society, vol. 42, no. 3, pp. 604-612, 2017, in Chinese. 


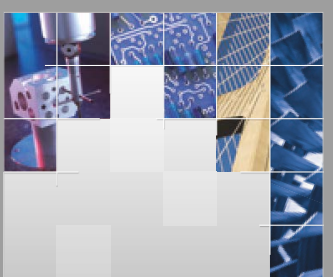

\section{Enfincering}
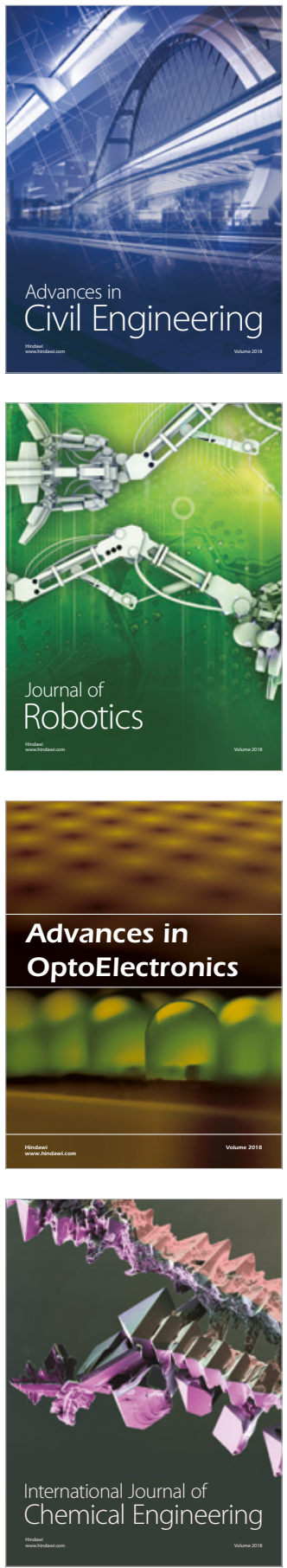



\section{Rotating \\ Machinery}

The Scientific World Journal

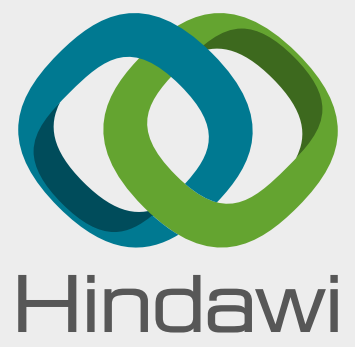

Submit your manuscripts at

www.hindawi.com

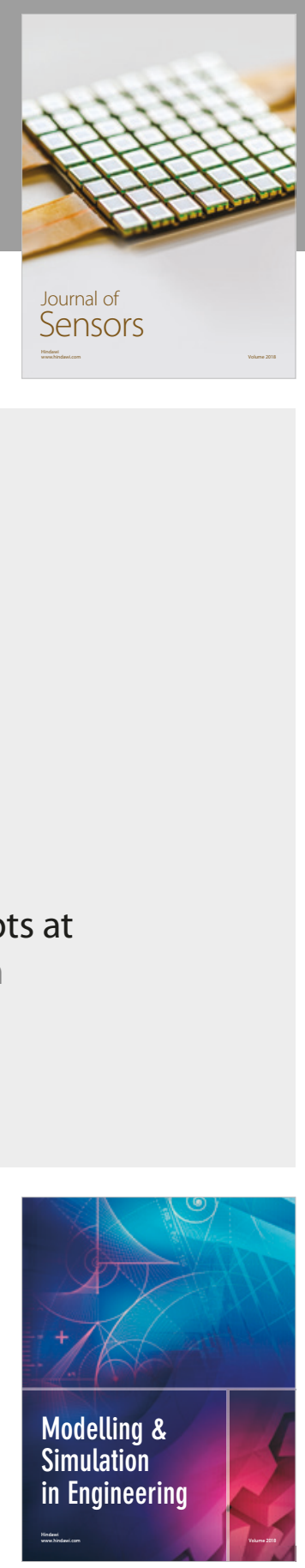

\section{Advances \\ Multimedia}
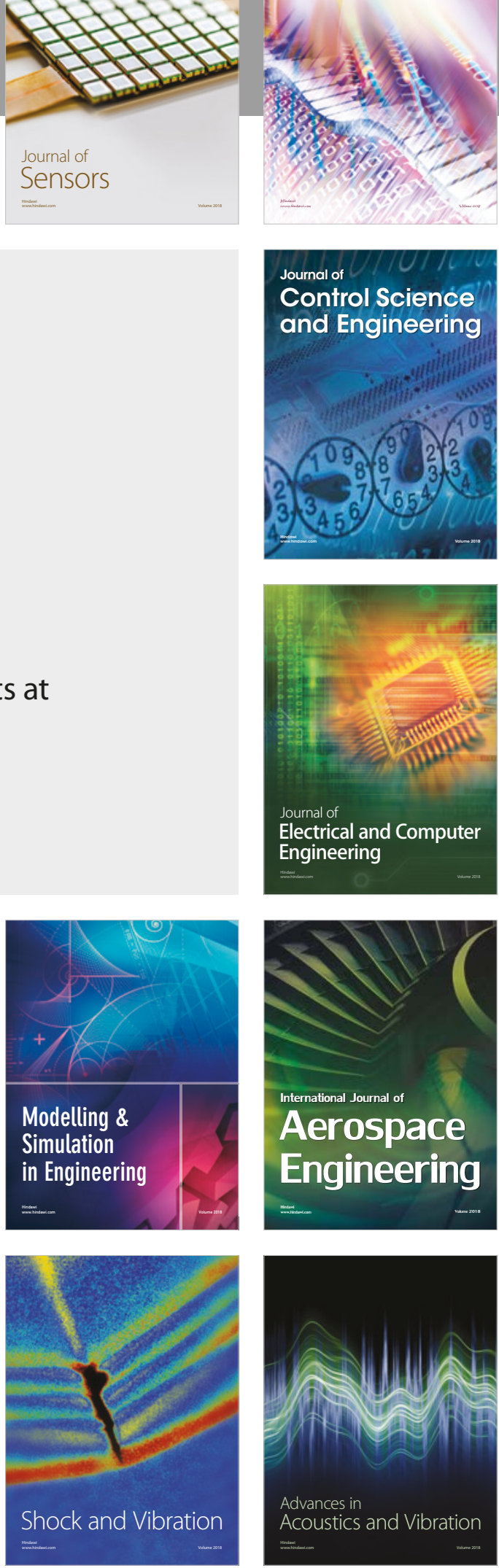